European Journal of Business and Innovation Research

Vol.8, No.3.pp. 36-49, May 2020

Published by ECRTD-UK

Print ISSN: 2053-4019(Print), Online ISSN: 2053-4027(Online)

\title{
RECONCEIVING SUPPLY CHAIN (SC) RISK MANAGEMENT STRATEGIES WITH THE OUTBREAK OF PANDEMIC LIKE COVID-19
}

\author{
Shish Haider Chowdhury \\ Director, Central Procurement Technical Unit (CPTU) \\ IMED, Ministry of Planning, Dhaka, Bangladesh \\ Certified National Trainer on Public Procurement in Bangladesh \\ Md. Aknur Rahman \\ Deputy Director (Deputy Secretary) \\ Central Procurement Technical Unit (CPTU) \\ IMED, Ministry of Planning, Dhaka, Bangladesh \\ Certified National Trainer on Public Procurement in Bangladesh \\ Mohammed Salah Uddin \\ Deputy Director (Senior Assistant Secretary) \\ Central Procurement Technical Unit (CPTU) \\ IMED, Ministry of Planning, Dhaka, Bangladesh \\ Certified Project Management Professional (PMP), PMI, USA
}

\begin{abstract}
Supply Chain (SC) is becoming more and more interconnected and globalized in the recent days and hence, with the outbreak of COVID-19, it has engulfed the whole supply and distribution systems of the world affecting the every aspect of human life. SC itself contains some risks as the name suggests and there are many robust SC risk management strategies in place to address the risks. With the outbreak of COVID-19, SC risk management strategies are encountered and SC professionals are trying to explore the strategies like intervention of ICT, supplier base optimization, improving SC visibility, stressing more importance on the free flow in data and information, risk diversification and so on. The article attempts to identify the extent of the SC risk management strategies and finally put forward some recommendations to address those risks in the each segment of the $S C$.
\end{abstract}

KEYWORDS: supply chain, risk management process, risk triggers, tiering, collaboration

\section{INTRODUCTION}

With the recrudescence of the COVID-19, the whole world has been experiencing a bitter taste which drives the Supply Chain (SC) and procurement professionals around the globe to rethink the basic fabrics of the SC. The structure of the basic SC has been shattered and twisted which may create the new and sophisticated risks in the overall management of SC. Organizations tend to develop a robust and effective risk management strategy to minimize cost, avoid unexpected disruptions to production, to mitigate SC vulnerability, to improve SC resilience, to improve business continuity, to respond to the outside factors as scandals, legislation, or regulation as mentioned by Sadgrove. The traditional SC risk management strategies are challenged in the face 
Print ISSN: 2053-4019(Print), Online ISSN: 2053-4027(Online)

of COVID-19. As the pandemic like COVID-19 is unique one and hence, it requires special attention so that future SC disruptions can be faced with some degree of confidence. In order to fulfill this gap, through this article, we will try to explore the scope and application of the SC risk management strategies which are in place and will try to investigate the significance of those strategies to face the new challenges faced by the outbreak of COVID-19.

\section{Supply Chain Risk Genesis}

International standard on risk management, ISO 31000-2018, considers risk as 'the effect of uncertain objectives'. Chartered Institute of Procurement and Supply (CIPS) defines risk as 'the probability of an unwanted outcome happening.' Risk can be originated from both the micro and macro environments as indicated in the figure below:

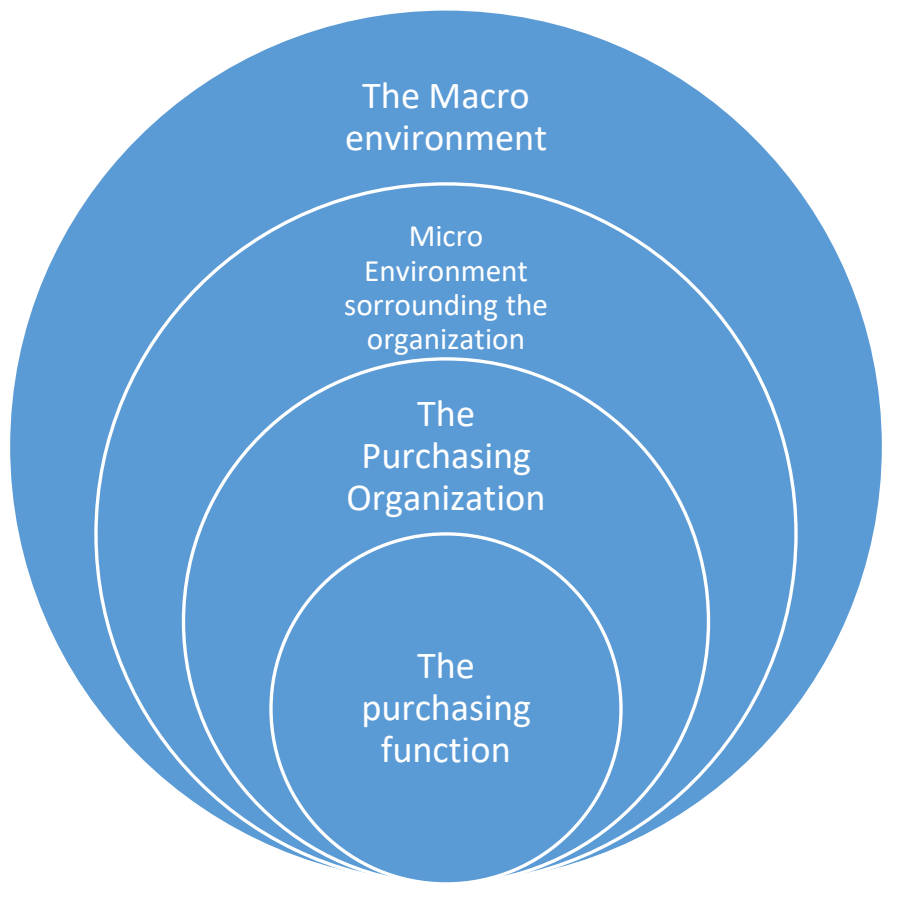

Figure 1: SC Risk Genesis (Developed by the authors)

Internal environment takes care the issues like organizational internal structure, leadership style, culture, systems, and governance systems and so on. Micro environment includes customers, suppliers and competitors who are impacted by the activities of the organization and macro environment considers those factors within which an organization operates/ interact like- market structure, level of competition in the industry, laws, regulations, politics, technology, global economic factors etc. 
Vol.8, No.3.pp. 36-49, May 2020

Published by ECRTD-UK

Print ISSN: 2053-4019(Print), Online ISSN: 2053-4027(Online)

\section{Identification of risk in the Supply Chain}

The existing literature suggests that supply chain, as it integrate more connectors with each other, it generates risk which need to be managed and addressed as indicated by Barry (2004), "An enterprise may have lowest overall costs in a stable world environment, but may also have highest level of risk- if any of the multiple factors kink up an elongated global supply chain." Risk identification, management, monitor and control are iterative process. Risks may be identified by means of applying various techniques such as-(a) STEEPLE, PESTLE and SWOT analysis (b) Process Audit (c) Scenario Analysis (d) Critical Incident Investigation (e) Market Intelligence (f) Horizon Scanning (g) Use of Risk Register (h) SC mapping. Project Management Institute (PMI) suggests the following tools and techniques for risks identification: brainstorming, checklists, interviews, root cause analysis, assumptions and constraints analysis.

\section{Categories of Risks in the Supply Chain}

$\mathrm{SC}$ is much more interconnected and diversified than ever before. The complexity and dynamic nature of the SC are increasing the dimensions of SC giving rise to newer and newer risks. SC risks may encompass- strategic risk, operational or functional risk, network risk, environmental risk, security risk, market risk, demand and supply risk, compliance risk, reputational risk, financial risk. Ghosal (1987) identified a broad categories of risks as (a) macroeconomic risks associated with significant economic shifts in wage rates, interest rates, exchange rates, and prices; (b) policy risks associated with unexpected actions of national governments; (c) competitive risks associated with uncertainty about competitor activities in foreign markets; and (d) resource risks associated with unanticipated differences in resource requirements in foreign markets.

\section{Risk Triggers}

It's quite a very tough task to determine the events which trigger SC disruptions. Some triggers of SC disruption may be controllable, some may be uncontrollable. Supply Chain and Transport Risk Survey in 2011, undertaken by World Economic Forum (WEF) identified some triggers which are depicted in figure 2. 
Print ISSN: 2053-4019(Print), Online ISSN: 2053-4027(Online)

Figure 2: Triggers of global supply chain disruptions

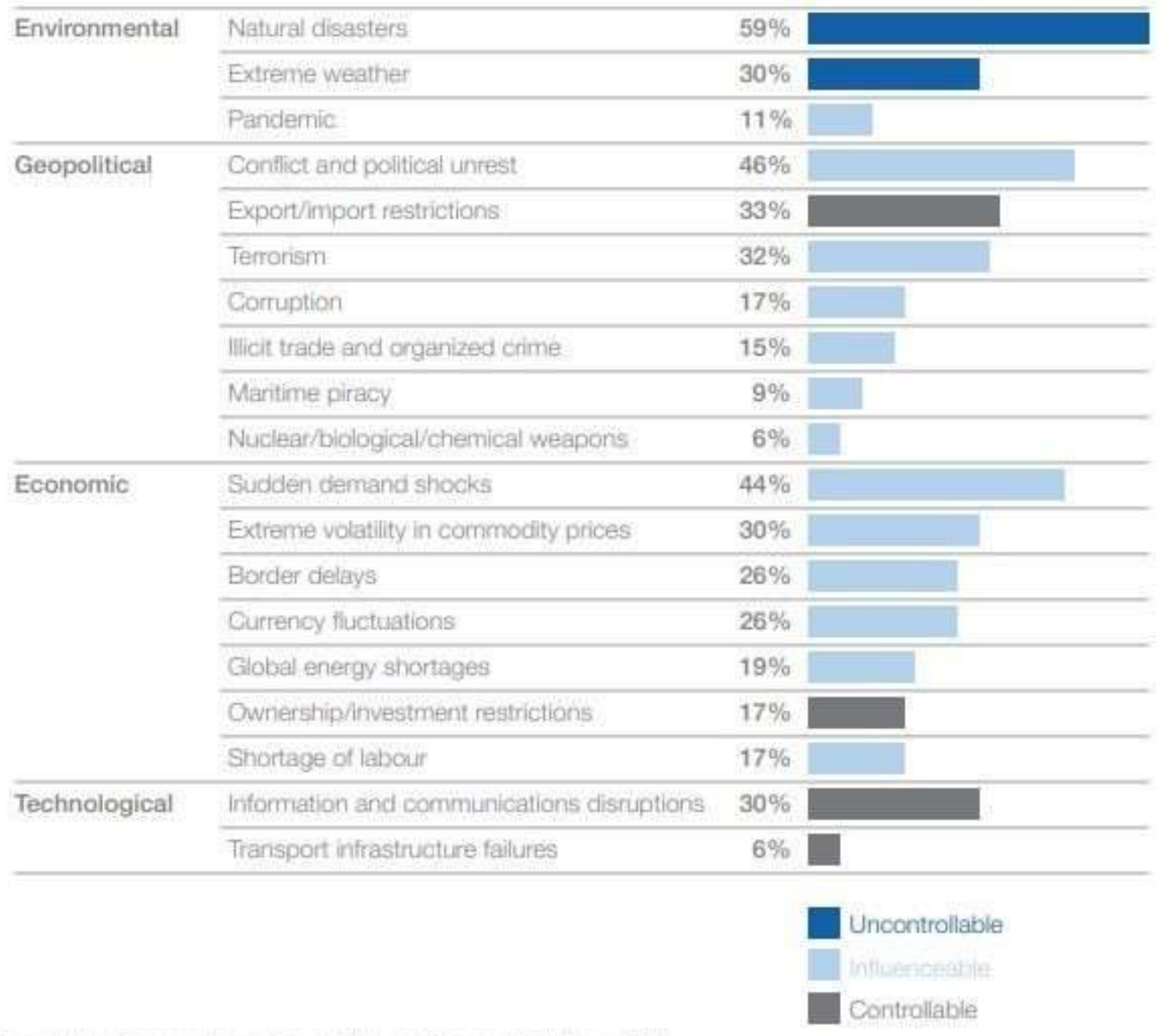

\section{Risk Assessment Tools and Techniques}

Risk can be assessed by means of qualitative and quantitative tools and techniques. Qualitative tools may include- risk assessment grid/ matrix, risk scoring, scenario analysis, bubble chart etc. And quantitative tools and techniques may include- simulation, sensitivity analysis, decision tree analysis, influence diagram, fault tree analysis and so on. Zsidisin et al. (2004), opines, "Purchasing organizations can assess supply risk with techniques that focus on addressing supplier quality issues, improving supplier processes, and reducing the likelihood of supply disruptions. From an agency theory perspective, these risk assessment techniques facilitate the obtaining of information by purchasing organizations to verify supplier behaviors, promoting goal congruence 
between buying and selling firms, and reducing outcome uncertainty associated with inbound supply."

\section{Principles of Risk Management}

The core principle behind the risk management is the value creation for the organization. It is an all pervasive integrated process combining both human and non-human elements ranging from the operation to strategic levels intended to improve organizational efficiency and support towards the achievement of organizational goals and objectives. Risk management principles outlined by the ISO 31000-2018 are mentioned in figure 3.

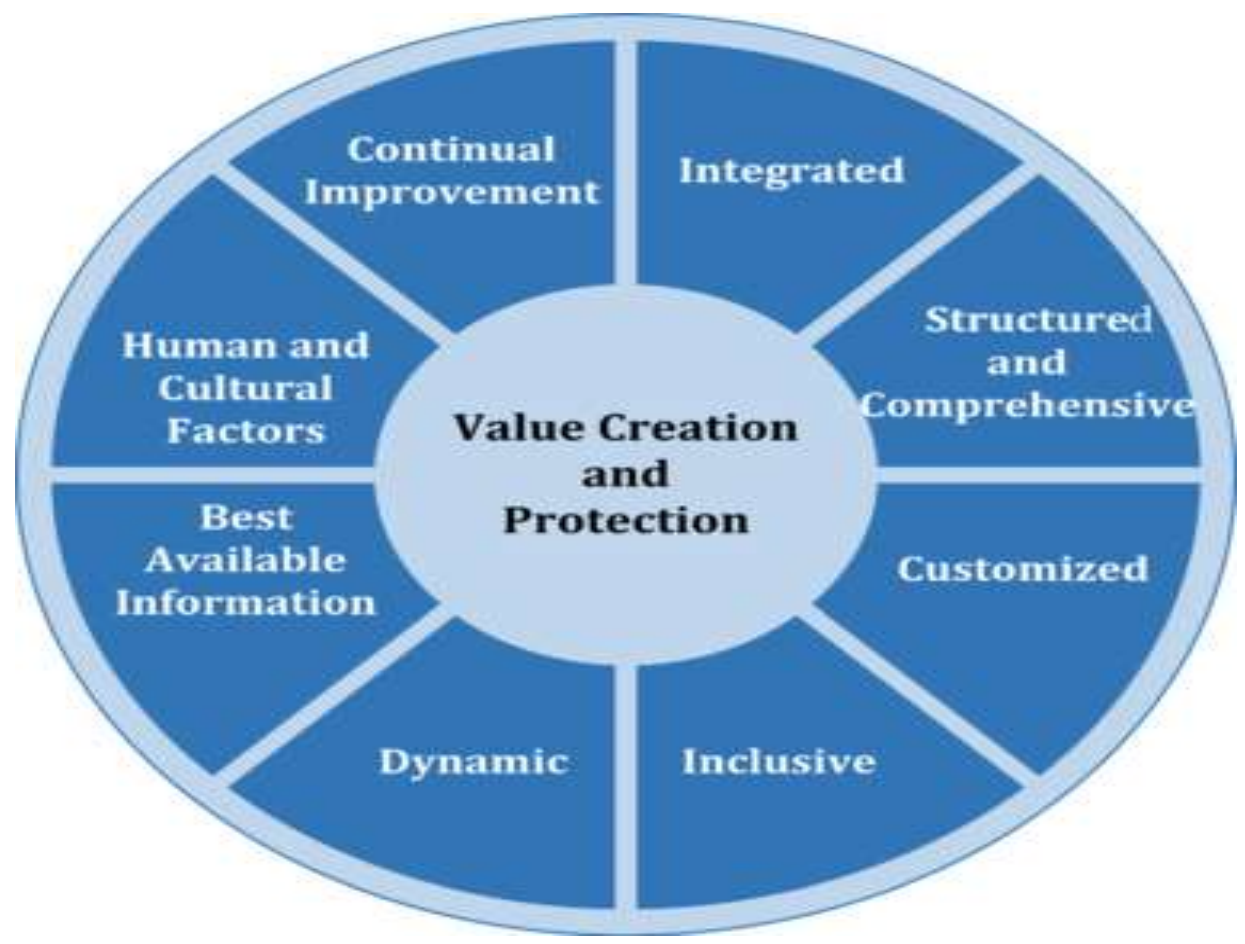

Figure 3: Principles of risk management (ISO 31000:2018)

\section{Risk Management Process}

Each and every SC has its instinct features and characteristics. In spite of that, management of the risk is universal and the modalities of managing risk may be tailored based on the nature of the industry within which the SC operates. The whole functionalities of the SC can be depicted in the figure 4. A robust risk management starts with the development of risk management plan and identification process and uses various methods to identify potential risks. After identification, risks are recorded in the risk register and then analyzed using different qualitative and quantitative 
tools and techniques. Through qualitative analysis, risks are prioritized and quantitative analysis is done only for those prioritized risks. After based on the result of risk analysis, different risk management strategies are applied and lastly, conduct control and monitoring activities are performed based on monitoring tools and techniques.

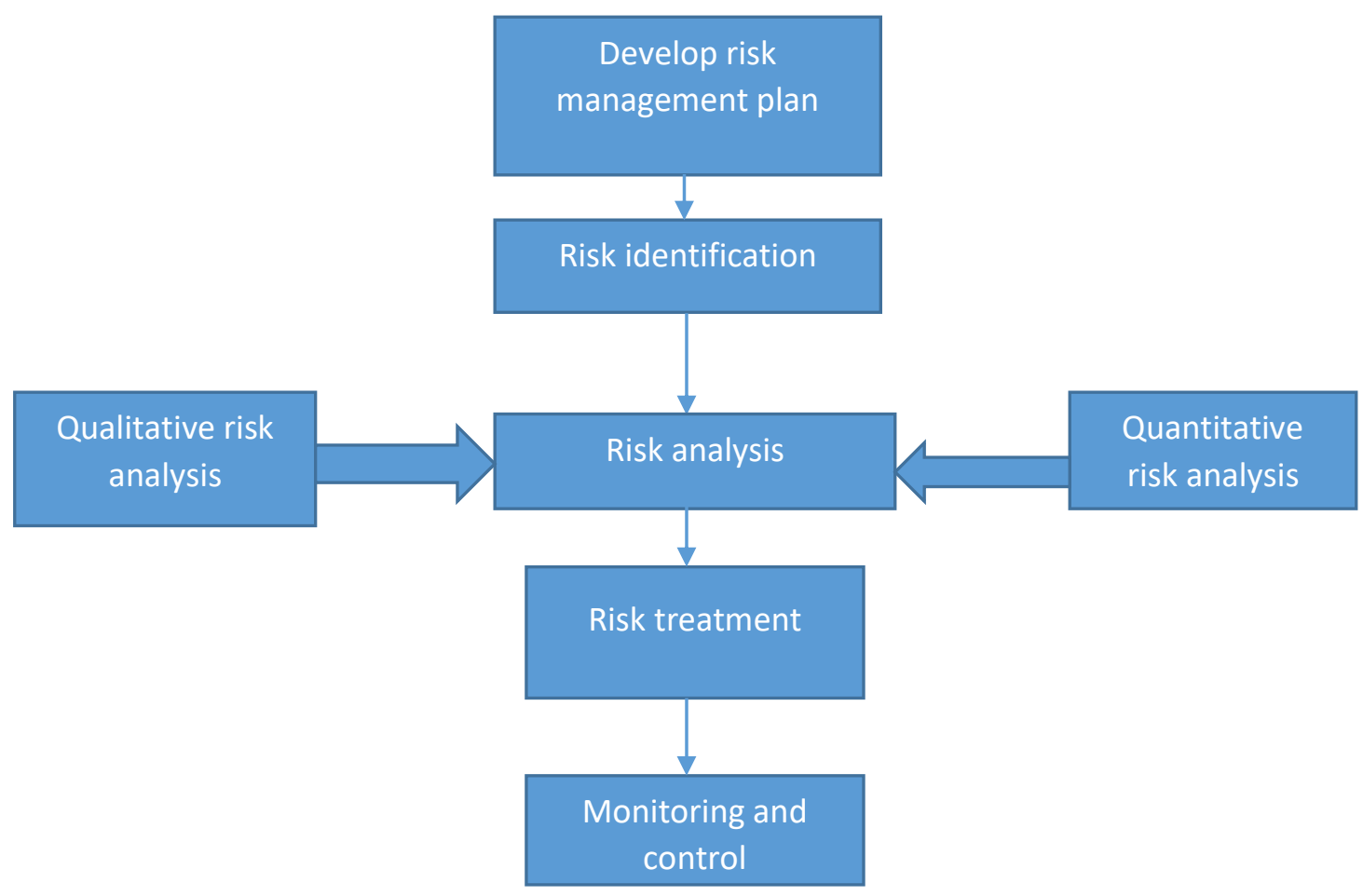

Figure 4: Risk Management Process (Developed by the authors)

\section{Supply Chain Risk Management Strategies:}

It's apparent to all concerned that any supply chain may be affected by the anticipated and unanticipated events within the inside and outside of the organizations. SC risk may occur upstream and downstream operations. Risk is inherent in nature and can't be eliminated fully, that is, by implementing robust and intelligent risk management, the impact and the probability of occurrence can be minimized. For example, Apple incorporation used force majeure language in the contract in those days of Tsunami in Japan back in 2011 and mitigated the negative effect of that black swan event. A recent study conducted by the 'Institute for Supply Management (ISM)' revealed that in the United States of America, $44 \%$ of the respondents opined that there were no plans to address disruption from China. The interactions and the operations between the SC players need to be clearly visible as is said by the Sri Talluri- a professor of Supply Chain Management at 
European Journal of Business and Innovation Research

Vol.8, No.3.pp. 36-49, May 2020

Published by ECRTD-UK

Print ISSN: 2053-4019(Print), Online ISSN: 2053-4027(Online)

the Michigan State University. He opined that lack of visibility of the SC became the real problem of manufacturers in the USA (www.supplychaindive.com). With the outbreak of COVID-19, the lead times is also increased. CEO, ISM said in a statement, "For a majority of U.S. businesses, lead times have doubled, and shortage is compounded by the shortage of air and ocean freight options to move product to the United States- even if they can get orders filled." It is noted that there was a major paradigm shift in the pattern of demand of the consumers. Demand is shifting from shop stores to online channels as the consumers fear to be infected with the COVID-19 and avoid human touch. In Bangladesh, it is observed that the online shopping platforms like Chaldal.com, Ghore Bazar.com, e-valey, Daraz.com. Priyo Shop.com, Khash Food, Ajker deal.com, Othoba.com, Meena Click.com, Shapno.com are with superfluity of orders and are under tremendous pressure from the consumers and these online shops are taking much more time compared to regular timing. Another aspect is to maintaining the optimum stock of inventory as per Economic Order Quantity (EOQ) rule. It's quite judicious to have a strong inventory replenishment system as is used by the GUCCI. The CEO of GUCCI, said, "We are now brandby- brand reallocating that inventory to the other regions of the world to make sure that we are not too heavy stock in China". According to Reuters, present US government is taking steps to move US production and SC dependency from China and US companies are given tax incentives and reshoring subsidies for moving both sourcing and manufacturing out of China (The Daily Star on $4^{\text {th }}$ May 2020), i.e. USA is trying to diversify her SC at the risk of COVID-19. As part of the management of SC risk, NIKE fine- tuned its operations with more focus on the inventory visibility and demand sensing. In the field of supply chain, use of 4T's approach is very popular one, i.e. Tolerate (accept) the risk. When the impact or likelihood of the risk is negligible, the risk can be accepted. Second approach is the Transfer (spread) of the risk- may be implemented by pursuing third party insurance coverage. The third approach is the Terminate (avoid)- is used when the organization thinks that the likelihood or impact cannot be reduced, for example, during COVID19, all the scheduled international sporting events have been suspended and it's better to avoid undertaking any contract with the advertising company for the sporting event. The fourth approach is to Treat (minimize or mitigate) of the risk- meaning taking effective steps to minimize the likelihood or impact. For instance, during COVID-19, most of the Chinese companies have failed to supply orders. In that case, sole dependency on the Chinese companies can jeopardize the SC. Therefore, it's rather better to diversify the supplier base and mitigate the risk of being vendor locked.

\section{RETHINKING THE STRATEGIES}

\section{Risk Mapping}

Based on the impact and probability of occurrence, the SC professionals need to map the SC which will help in identifying the strength and weakness of the SC as developed by Sadgrov which is depicted figure 5. The figure indicates that the event like terrorist attack may be very unlikely to 
happen. In current SC disruption caused by COVID-19 may be a very unlikely event with catastrophic and significant impact. On the other hand, employee may steal something and occurring of this event is quite probable having insignificant impact on the organization. Therefore, based on the probability and impact using this matrix the organizations may create a watch list of risks.

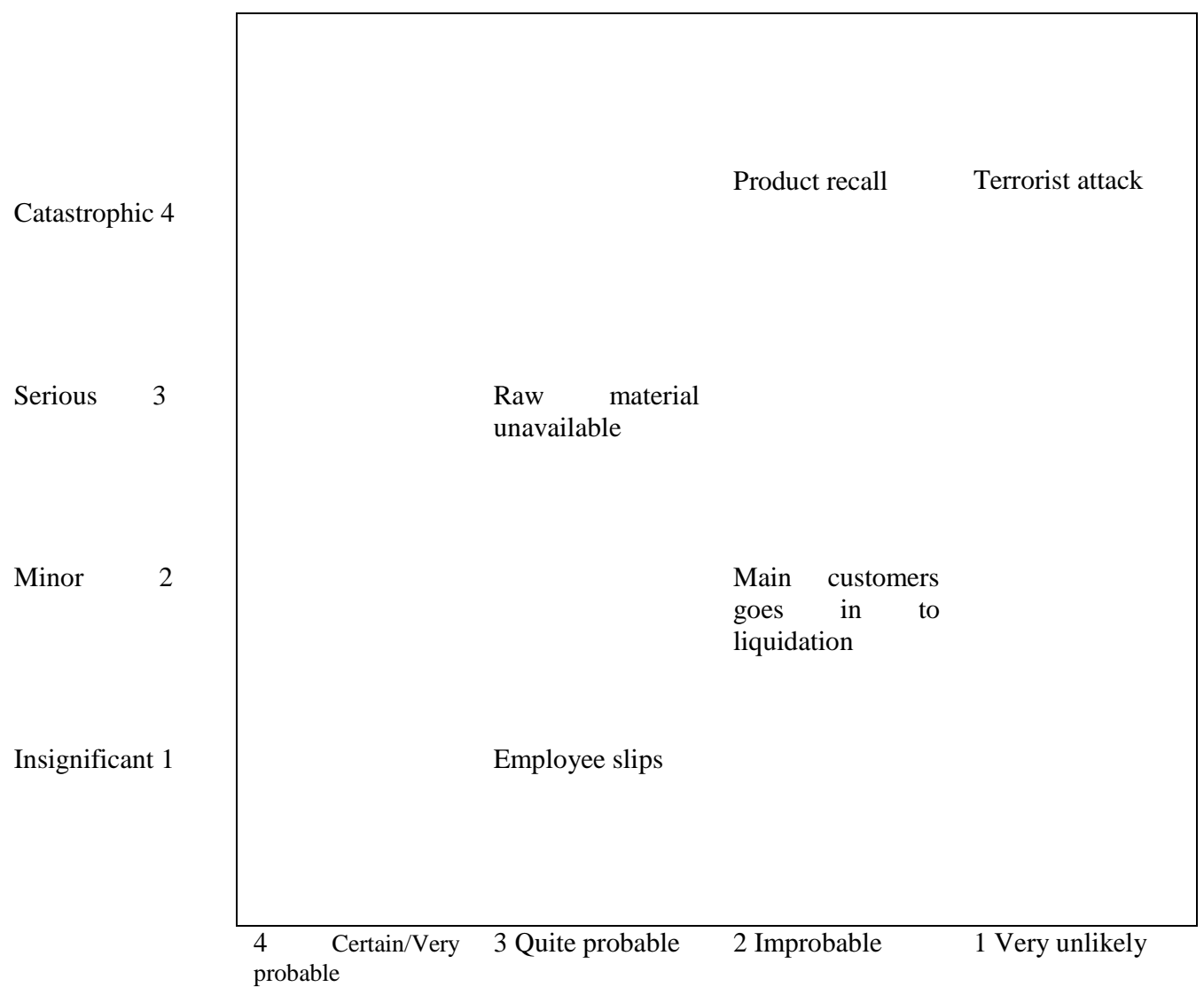

Figure 5: Qualitative risk matrix

\section{Investing in Visibility Tools}

It is very imperative in the present day situation that the firms invest more in the Digitized Supply Chain (DSC) which will make the interactions of the SC players more visible. To ensure Order Visibility (OV), real time orders may be placed, to ensure Carrier Visibility (CV), electronic notification like EDI, GPS, may be used, to ensure Warehouse Visibility (WV) goods may be received, stored and sent electronically. 


\section{Synchronization of Demand and Supply}

During any pandemic, the organizations may have capability to prioritize the needs and demand of the customers as is done by Amazon.com. Recent reports reveal that Amazon.com has restricted the supply of non-essential goods to customers in France and Italy. It focuses only the items which are more essential in nature and urgently needed during the crisis. Daily global demand and supply optimization is expected as is used by the NIKE. The supply chain managers need to identify the appropriate risk mitigation strategy to pinpoint production downtime, locations of the suppliers, and probable potential epicenter of COVID-19 within the supply base and the degree and intensity of quarantine and take actions accordingly.

\section{Focusing on Tier 1 (Direct) and Tier 2 (Secondary) Suppliers}

The organizations which are heavily dependent on the Tier 1 (Direct) and Tier 2 (Secondary) suppliers in China are the worst disrupted. Supply chain professionals have to deal with the hundreds of suppliers, and countless number of parts in different tiers. Tier 1 suppliers may be the main contact of organizations and the relationship spectrum does not stop here. These Tier 1 suppliers may be dependent on Tier 2 tiers and so on. This is a complex web and contain the instinct of chain reaction.

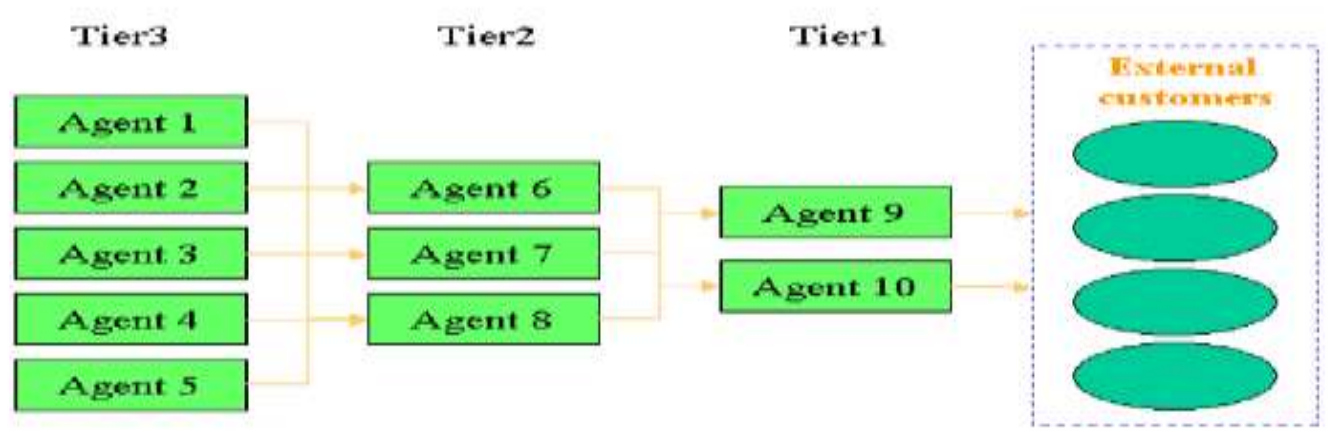

Figure 6: Supply Chain Tiering (Developed by the authors) 
European Journal of Business and Innovation Research

Vol.8, No.3.pp. 36-49, May 2020

Published by ECRTD-UK

Print ISSN: 2053-4019(Print), Online ISSN: 2053-4027(Online)

\section{Better Supplier Relationship}

Maintaining better supplier relationship is very crucial during and after COVID days to make the global SC more responsive. The outbreak of COVID forced the organizations to think in a nontraditional alternate way. For example, many firms have started to use WhatsApp, Microsoft meeting, Webex, Skype, Zoom meeting and so on and are being connected virtually with the strategic partners/ suppliers and exchanging their views. Some may argue that the COVID-19 has created this opportunity to understand each other, communicate and share with each other on real time basis which ultimately contribute to have a healthy SC.

\section{Maintaining Collaboration in the Areas of Buying and Logistics}

A survey conducted by SM and CIPS revealed that $41 \%$ of the surveyed respondents intended to maintain collaboration in the areas of buying and logistics. Long term collaborative relationship needs to be maintained particularly as mentioned in the Kraljic Matrix which categorizes at upper right quadrant as critical item (during COVID-19 we may refer to PPE, PCR machine and other medical equipment).

\section{Looking for Alternative Suppliers}

The US does not produce sufficient quantity of N95 respirators for which it has to depend on China. During COVID-19, China stopped exporting N95 as her domestic demand rises. So, it's very imperative to recognize the issue of alternative sourcing. It is worth mentioning that in the COVID-19 crisis, the firms started thinking to increase dependency on the domestic sourcing taking cognizance in to the competitive cost advantage and to this end necessary structural change in the SC is highly sought as is indicated by the Thomas Survey in the USA.

\section{Traceability in Supply Chain}

Track and Traceability is one of the important facets of the today's complex and global SC. It is of paramount important to have crystal clear idea regarding the "real-source-level information"meaning the origin, source, packaging, may be other information regarding the product characteristics. Fish industry in the SC may be cited as an example. After catching fish in the sea, that fish may be sent to low cost country like China, Bangladesh and India to get accessed to low cost of processing for doing some jobs, may be cleaning and sorting. Having semi- marketable fish, it can be sold to the major markets before packaging. In the final stage, fish is packed as per the requirements of the major super markets/ restaurants of the world. Any SC to be reliable and responsive, the SC professionals must see whether there is any gap in any stage of value addition and processing and consequently determine the visibility risk. This can be traced by using 
European Journal of Business and Innovation Research

Vol.8, No.3.pp. 36-49, May 2020

Published by ECRTD-UK

Print ISSN: 2053-4019(Print), Online ISSN: 2053-4027(Online)

electronic data driven real time online monitoring system so that effective and widespread SC visibility is achieved and overall SC risk is minimized.

\section{Private- Public Sector Cooperation}

COVID-19 is possessing some unique features and is causing serious public health hazard without precedent in living memory, is completely different in nature. It may require total and concentrated cooperation from-including governments, international organizations, business community and civil society. An integrated approach to SC risk management may be devised and this approach may also be tailored and customized based on the individual country perspective and degree of international integration. It is a matter of hope that World Economic Forum (WEF) is working to this end to bring the world leaders to a common platform in order to face the unprecedented pandemic. In Bangladesh scenario, it is seen that private sector is coming forward to join hands with government with different initiatives. A living example may be cited here that, Bangladesh Garments Manufacturers and Exporters Association (BGMEA) is instructed five its member companies to produce 500000 PPEs to hand over to the government for its use to combat the crisis period.

\section{Flexibility in Supply Chain}

By adding flexibility to SC, management of the procuring agencies are able to respond to deviations from the surroundings of the chain, as well as fluctuation from within the chain. For the short term, such flexibility may respond to changes in demand or supply quickly and handle external disruptions effectively. It is high time the SC professionals could create flexible SC. For example, based on the criticality, urgency and strategic change of direction, the organizations can convert its production line to adapt the new requirements. Legal flexibility to accept digital signatures to avoid human contact and easy customs formalities for critical goods.

\section{Potential Opportunities for Bangladesh}

Bangladesh can have the full potentialities to transform the challenges coming out from the outbreak of COVID-19 in to opportunities. Most of the Fortune 500 global companies including Apple and other US companies are moving out of China, Bangladesh may take the advantage of this opportunity. With the new thinking of SC which emerges in response to the COVID-19, SC traceability will be increased and expanded, and Bangladesh can take the benefit by attracting the SC niche from the world market. As the USA and other Fortune global 500 companies are trying to explore new sourcing, Bangladesh may continue exploring the new possibilities. Dun and Bradstreet cited that top products imported from China may go to other destinations as described in the table below: 
European Journal of Business and Innovation Research

Vol.8, No.3.pp. 36-49, May 2020

Published by ECRTD-UK

Print ISSN: 2053-4019(Print), Online ISSN: 2053-4027(Online)

\begin{tabular}{|l|l|}
\hline Name of the product & Possible alternative supplier country \\
\hline Electrical machinery, equipment and parts & Brazil \\
\hline Nuclear reactors, boilers and parts & Chile, Singapore \\
\hline Furniture and parts & Mexico \\
\hline Toys, games, and sports requisites & Mexico, Brazil \\
\hline Plastics and article made of plastics & Mexico, Brazil \\
\hline Motor vehicles and parts & Chile, Colombia, India \\
\hline Apparel and clothing accessories & Brazil, Canada \\
\hline Optical, medical and surgical instruments & Colombia, Brazil, India \\
\hline
\end{tabular}

\section{SOURCE: Dun \& Bradstreet}

If we have a closer look at the report of Dun and Bradstreet, it is found that Bangladesh has potentialities to prepare and make those products identified in the list and Bangladesh can, through her foreign diplomatic mission, explore the potential market diversification.

\section{CONCLUSIONS AND RECOMMENDED FURTHER ACTIONS}

As it is seen that today's SC is globalized, specialized, leaner and Just-In-Time (JIT) focused and this features made the global SC more complex and vulnerable. So, in order to make the global SC more agile and resilient, the following further actions may be adopted:

- Making supply network more visualized. SC visualization is more than just SC visibility. It provides context by visualizing the $\mathrm{SC}$ using location-based information;

- Navigating risks with digital tools, for example, use of Big Data Monitoring, machine learning, and $5 \mathrm{G}$ and so on;

- Developing mechanisms to forecast demand on real time basis and may be directed to the supply points accordingly;

- Using Artificial Intelligence (AI) to trace and track the gaps in the SC and to improve the data exchange and accuracy and send real time alert;

- Improving national and international risk resilience standards. In the context of disaster risk, e.g. COVID-19 situation, the ability of a system, community or society exposed to hazards to resist, absorb, accommodate, adapt to, transform and recover from the effects of a hazard in a timely and efficient manner;

- Adopting 'Digital First Distribution Strategy'. Apart from being present where prospects are there, another reason it's important to focus on digital-first is because digital prioritizes targeted distribution in a way that traditional presentation doesn't;

- Sharing data for hyper-vigilance. It may be more applicable for medical products. 
European Journal of Business and Innovation Research

Vol.8, No.3.pp. 36-49, May 2020

Published by ECRTD-UK

Print ISSN: 2053-4019(Print), Online ISSN: 2053-4027(Online)

- Using block chain technology for ensuring data privacy for the suppliers and increasing the SC visibility at sub-tier level;

- Making sound Business Continuity Planning (BCP) and Business Succession Planning (BSP). Sound BCP identifies which systems and processes must be sustained, and detail how to maintain them. And the BSP encompasses not only top- level management, but also can cover issues such as the procedures necessary for a successful transfer, legal and financial considerations;

- Implementing risk- informed SC strategy. Although Bangladesh has made significant progress in disaster risk management in other areas, the country is still at risk in the unprecedented adversities, namely COVID-19. Inclusive risk- informed public and private initiatives may aid in great extent in the process.

\section{References}

Barry, J. (2004). Perspectives: supply chain risk in an uncertain global supply chain environment. International Journal of Physical Distribution \& Logistics Management, 34 (9), 695-7

George A. Zsidisin, Lisa M. Ellram, Joseph R. Carter, Joseph L. Cavinato (2004). An analysis of supply risk assessment techniques. International Journal of Physical Distribution \& Logistics Management. Retrieved on $11^{\text {th }}$ May 2020 from

https://www.emerald.com/insight/content/doi/10.1108/09600030410545445/full/html

Ghoshal, S. (1987). Global strategy: an organizing framework. Strategic Management Journal, 8 (5), 425-40A guide to the project management body of knowledge (6th ed.), PMI

https://www.cips.org/knowledge/procurement-topics-and-skills/risk-mitigation/risk- analysis and -management/. Retrieved on $2^{\text {nd }}$ May 2020

https://www.cips.org/supply-management/analysis/2020/april/-are-we-entering-a-new-era-ofcollaboration/. Retrieved on $5^{\text {th }}$ May 5, 2020

https://spendmatters.com/2020/04/21/driving-supply-chain-risk-strategy-during-coronavirus recovery /. Retrieved on $3^{\text {rd }}$ May 2020

https://www.cips.org/supply-management/analysis/2020/april/what-can-a-tilapia-teach- $\quad$ youabout-tracing-your-supply-chain/. Retrieved on $20^{\text {th }}$ April, 2020

https://www.supplychaindive.com/news/suppliers-outside-china-coronavirus/572287/. Retrieved on $5^{\text {th }}$ May 6, 2020

https://www.weforum.org/agenda/2020/04/covid-19-coronavirus-bangladesh/. Retrieved on $4^{\text {th }}$ May 2020

https://www.weforum.org/agenda/2020/03/covid-19-coronavirus-lessons-past-supply-chaindisruptions/. Retrieved on $3^{\text {rd }}$ May 2020

https://www2.deloitte.com/global/en/pages/risk/articles/covid-19-managing-supply-chain-riskand-disruption.html. Retrieved on $3^{\text {rd }}$ May 2020

https://www.cnbc.com/2020/02/17/coronavirus-could-impact-5-million-companies- worldwideresearch-shows.html. Retrieved on $5^{\text {th }}$ May 202

Sadgrove, K. The Complete Guide to Business Risk Management (3rd ed.). Retrieved on 2nd May $2020 \quad$ from https://books.google.com.bd/books?id=IJq4BwAAQBAJ\&printsec=frontcover\&redir_esc 
European Journal of Business and Innovation Research

Vol.8, No.3.pp. 36-49, May 2020 Published by ECRTD-UK

Print ISSN: 2053-4019(Print), Online ISSN: 2053-4027(Online) $=\mathrm{y} \# \mathrm{v}=$ onepage $\& \mathrm{q} \& \mathrm{f}=\mathrm{falsehttps://www.iso.org/obp/ui/ \# iso:std:iso:31000:ed-2:v1:en.}$ Retrieved on 2nd May 2020 